Since the reactivity of patients varies enormously ac ?ording to their sensitiveness and how far this is covered by tolerance, it is well to begin with a do se so low that it is certain to be ineffective. Actual dosage I shall not mention here, since I have long discarde d the standards usually adoptr $d$ a id measure my tuberc alin in cubic millimetres of oricin ul solution; and though this is the best and simplest of all methods, the doses in a new standard would be difficult to grasp in a lecture. Having begun with this small dose, it may be very rapidly raised till some effect is noted. This must be looked for in a local reaction, or, failing this i n some slight general effect, such as a flattening of the temperature, or a slight rise, or slight symptoms in the paticnt. Having reached this point, the doses must be raised more gradually, and for the graduation of dosage nothing is more suitable than a geometrical progression such as that supplied by Lawrason Brown in Klebs's Texthook of Tuberculosis. By this means risk of large reactions is reduced to a minimum, and yet, with skilful adjustment, the dose may be kept sufficiently near the reacting point to efficiently call forth an immunizing response, the main points of which we have already laid down as the slight focal hyperaemia and the stimulation of antibody formation. It is unlikely that fever reactions will be altogether avoided, and this brings us to a parting of the ways among various exponents of the art of tuberculin administration. There are, as you know, certain people who ignore reactions, and, in their struggle to establish tolerance to large doses, will allow the patient to react violently again and again. Those who have treated localized tuberculosis, where the foci of clisease are under the eye, cannot look on this method with favour. They know how caseous material will soften and discharge itself under large focal reactions, and though such a process in the lung may in certain cases be inevitable and lead to no harm, in other cases this is far from being the case.

By avoiding such large reactions we are putting possible danger on one side. By allowing mild reactions occasionally, and keeping the dose near the reacting point we are fulfilling those conditions which experience has taught us to rely on in the treatment of visible lesions. In this way the whole course of treatment is directed towards the healing of the tuberculous areas, and tolerance is but a valuable by-product of the tuberculin administration. This may be called the method of utilizing reactions. A third method in the administration of tuberculin aims at the avoidance of all reactions, and las not much to recommend it unless its safety

The consideration of the method of pushing the dosage through reactions, with the aim of rapidly reaching tolerance to large doses, tempts me to the question of the value of such tolerance. Is there sufficient evidence of its value to justify us in making it an aim? If we turn to animal experiment for a moment we find that tuberculous disease protects against further infection with the tubercle bacillus. Experiments have been done on cattle, guineapigs, and, more recently, apes, which show that if virulent bacilli are injected into a healthy animal, no symptoms follow immediately, but after an interval symptoms of tuberculosis appear, and the animal dies. If similar injections are given to a tuberculous animal, on the other hand, a violent "reaction" immediately follows, but the animal shows no fresh tuberculous disease. Here we find that sensitiveness to tubercle products (not tolerance) is associated with protection against fresh infection. We might, thercfore, fear that by producing tolerance we were removing a valuable safeguard against the further spread of disease.

We are, it is true, removing from the patient, for a time, the power of autoinoculating himself, and this might be a danger where tuberculin was withheld. It is, however, highly unlikely that tolerance removes in any way the power of the tissues of the tuberculous to deal with the tubercle bacillus. More probably the injected tuberculin is "activated" as before, and tolerance only protects the tissues, the nervous system, and focus of disease, from the toxic effect which follows. This may be by the production of some such body as the "antituberculin" of Wassermann, which is shown to increase under tuberculin administration on the intensive system. If this is the case the condition underlying tuberculous sensitiveness is not removed, but its effects are mitigated.

On the other hand, there is no reason to suppose that tolerance adds anything to immunity against further disease, and for this reason the common use of the word "immunity" where tolerance is meant is greatly to se deprecated. All that tolerance does-and this is no small advantage, is to free the patient from those symptoms of autotuberculin poisoning which were undermining his health, and from dangerous focal reactions, which were spreading the disease. At the same time it enables us, as we have seen, to treat autotoxic disease with doses of tuberculin so large as not to be unduly interfered with by autoinoculation. The value of tolerance depends, then, on the need of it in any particular case, and not in all cases of phthisis is tolerance to large doses required or even advisable. The need, on the other hand, of obtaining repeated response to tuberculin, in the form of mild focal reaction and antibody stimulation, is common to all varieties of tuberculosis. This appears to be Nature's method of cure, and if it is followed on rational lines, and the needs of each individual case carefully studied, it will be found that we have in tuberculin, and the control of autotuberculin, all or nearly all that we need for the cure of tuberculosis.

At the end I must apologize that I have tried to cover an impossibly wide field in this lecture. Its title was hurriedly supplied many months ago, and I did not realize at the moment to how big a business I was committing myself.

\section{A THIRD SERIES OF TWENTY CASES OF PULMONARY TUBERCULOSIS TREATED BY CONTINUOUS ANTISEPTIC INHALATION.}

By DAVID B. LEES, M.D.Cantab., F.R.C.P.Lond., CONSCLTING PHYSICIAN TO ST. MARY'S HOSPITAL, AND TO THE HOSPITAL FOI SICK CHILDHEN, GREAT ORMOND STREET.

IN a paper read before the Therapeutical Section of the Royal Society of Medicine on November 2nd, 1909, and published in the Proceedings of that Society, and also in the British Medical Journat of December 11th, 1909, I advocated the treatment of incipient and early pulmonary tuberculosis by means of continuous antiseptic inhalation, and narrated 30 cases in which it had been employed with success. In a second paper, printed in the Lancet of November 19th, 1910, I related 20 additional cases similarly treated; some of these were advanced or complicated cases. I desire now to record a third series of 20 cases, making a total of 70 cases treated by the method of which full details were given in my first paper.

\section{Case 51.}

A patient, aged 26, a draper's assistant, was sent to me by Case 3, July 29th, 1910. His sister died seven years ago from phthisis at the age of 23 years after eight months' illness. Ho had suffered for eighteen months from repeated "colds" and frequent cough, with occasional slight haemoptysis. In March, frequent cough, with occasional slight haemoptysis. In March, 1909 , he entered a sanatorium and remained in it twelve weeks
(weight on admission $10 \mathrm{st}$. $1 \mathrm{lb}$. - it rose to $10 \mathrm{st}$. $12 \mathrm{lb}$., but fell again to 10 st. $81 \mathrm{lb}$.). Since June 20th, 1909, he bad been at work, and had again " caught cold." His cough and sputum were as troublesome as before he entered the sanatorium, and his weight was only $9 \mathrm{st} .12 \mathrm{lb}$. Cough was frequent, short, and loose-lie expectorated into a flask. He looked wasted, worn, and ill. All the characteristic dull areas of pulmonary tuberculosis 'as described in my first paper) were present, and those culosis 'as described in my first paper) were present, and those
at the left upper and lower apices were specially large. Over at the left upper and lower apices were specially large. Over
the whole left upper lobe in front and at both lower apices there was marked crepitus on inspiration, and very defective air entry at the right upper apex.

He was advised to remain in bed for two weeks and practise continuous antiseptic inhalation in the method and with all the details mentioned in my first paper. I saw him a second time on August 15th, 1910; he had then lost another pound, the weight having fallen to 9 st. $11 \mathrm{lb}$. But his cough was less troublesome, his sputum less profuse, his dull areas distinctly smaller, and the pulmonary crepitant sounds were much diminished.

He persevered with the treatment, and on September 26th, 1910, was much better, felt "quite a different man." Cough was "very much better," and sputum "very much less." His evening temperature was still about $99.4^{\circ} \mathrm{F}$. morning $97.8^{\circ} \mathrm{F}$.). His weight was still 9 st. $11 \mathrm{lb}$., but he felt very much stronger, His weight was still 9 st. $11 \mathrm{lb}$, but he felt very much stronger, and no longer fatigued by walking. "Felt as if he would not recover at the last visit, but now feels that he is getting well."
The physical signs showed an increased improvement. Had not been able to wear his inhaler at night. He spent the next four months at Southbourne. wearing his inhaler about eight 
hours out of the twenty-four, but the weather was unfavourable and he had uncomfortable lodgings. When I saw him again (February 23rd, 1910) he had lost $41 \mathrm{~b}$., but the pulmonary signs were no worse, and he had hardly any congh. During the next month he gained $21 \mathrm{lb}$., but after this there was a steady loss. Of late he had used his inhaler only five hours daily. He was urged to remain in bed for a fortnight and inhale continuously day and night. Some temporary improvement followed. In August he was admitted into Ventnor Hospital. Dr. Robertson, of Ventnor, has kindly informed me that he "died from tuberculous meningitis on September 1st, 1911, although he had gained $5 \mathrm{lb}$. up to the onset of cerebral symptoms, and in other respects was doing well."

This patient's personal and family history were extremely unfavourable, and the treatment by inhalation was imperfectly carried out. Yet he obtained very considerable relief.

\section{Case 52.}

A young man of 25, whose pulmonary symptoms had existed for two years before I first examined him on August 18th, 1910, and who had been in a sanatorium for eight and a half months (February-October, 1909). During the first five months of his stay in the sanatorium he gained no weight, but in the las three and a half months his weight rose from 11 st. $7 \mathrm{lb}$. to $12 \mathrm{st} .6 \mathrm{lb}$. Since his discharge he had been living in an open-air shelter at the seaside. He came to me on August 18th, 1910, on account of a "feverish cold," renewal of cough, and marked wasting. His weight was 11 st. $6 \frac{1}{3} \mathrm{lb}$. - - 1 lb. less than when he entered the sanatorium. He was found to have two cavities in the upper lobe of the left lung, and extensive signs elsewhere. Treatment by persistent antiseptic inhalation was advised, bu it was.imperfectly carried out. He objected to the inhaler at night, and, though he used it all day for twelve days, soon lessened the period of use to six hours, and finally to three hours. At his second visit on September 27th he felt better and the physical signs showed some improvement, but he had lost another $\frac{1}{2} \mathrm{lb}$., his weight now being only $11 \mathrm{st} .6 \mathrm{lb}$. He was strongly urged to wear the inhaler persistently, day and night, strongly urged to wear the inhaler persistently, day and night, and was warned of the danger of septic infection of his pul-
monary cavities. He acted on this advice to the extent of about eight hours daily, that is, for only about one-third of the time advised. Yet even with this imperfect use of the method he began at once to improve, and gained weight steadily. From 11 st. 6 lb. on September 27th, 1910, it rose persistently to $12 \mathrm{st} .6 \mathrm{lb}$. on March 8th, 1911. Thus, under treatment by antiseptic inhalation imperfectly carriec out, he gained $14 \mathrm{lb}$. in five and a half months-a larger amount than his previous gain in eight and a half $\cdot$ months in a sanatorium. The physical signs also steadily improved, and his evening temperature was normal. Encouraged by this improvement, he reduced the period of inhalation to only six hours daily. In July he caught "fresh colds," and the intense heat of this summer tried him much, the temperature in his outdoor shelter on one occasion rising to $100^{\circ} \mathrm{F}$. He lost weight rapidly, and when I saw him again on September 21st his weight was only $11 \mathrm{st}$. $7 \mathrm{lb}$, and there was evidence of extension of the disease in his lungs. He was advised to go to bed for a fortnight and to practise continuous inhalation (day and night). He did as advised, and when last seen, on November 22nd, 1911, looked and felt much better, and had gained $4 \mathrm{lb}$. in weight physical signs had also again imiroved quite definitely.

out, yet the benefit derived from it has been unmistakable.

Case 53.

A patient of Dr. Bousfield of Hornsey Lane, a clerk in an insurance office, recommended by Mr. A. (Case 25 of my first paper), who under treatment by continnous antiseptic inhalation for five months in 1909 made a complete recovery (including the obliteration of.a cavity), and who has since done his full work for two years.

The patient was brought by Dr. Bousfield on September 24th, 1910 , some tubercle bacilli having been detected in his sputum. The dull areas in his lungs were typical and extensive, bu auscultatory evidence was almost absent; there was defective air entry over the dull areas, but no crepitant sound, no prolonged expiration, and no audible whisper over the front of the chest, and only the slightest crepitant sound at one spot in the left lung posteriorly.

Under treatment by continuous antiseptic inhalation this patient made a rapid recovery. Dr. Bousfield brought him to me on October 28th, 1910, and again on December 7 th. On each occasion there had been a gain in weight, and the dul areas were smaller than at the previous visit. In the ten weeks he had gained $13 \mathrm{lb}$. After a stay at the seaside he went back to work at his office, and in October, 1911, I heard that he had been in full work since June, and that he looked extremely well. In November Dr. Bousfield wrote: "The sputum has been tested three times-in June, September, and last weekand no tubercle bacilli found. He has gained over a stone and a half in weight, and is better now than he has been for ten years." In reply to an inquiry Dr. Bousfield kindly sent word that the examinations for tubercle bacilli in the sputum wer carried out by the Clinical Research Association, Adelphi, with the appended results:

August, 1910. Tubercle bacilli present.

December, 1910. Tubercle bacilli present.

February, 1911. A small number of tubercle bacilli present. March, 1911. A few tubercle bacilli present.

June, 1911. No tubercle bacilli.
September, 1911. No tubercle bacilli.

November, 1911. No tubercle bacilli.

Dr. Bousfield also confirms the fact of the "progressive disappearance of the areas of dullness."

\section{Case 54.}

A man aged 33, a clerk, sent to me on September 26th, 1910, by the late Dr. Clark of Twickenham. Cough for ten weeks; much yellowish phlegm ; no haemoptysis. Weight, 10 st. $6 \frac{1}{2} \mathrm{lb}$.; last spring he weighed $11 \mathrm{st}$. $7 \mathrm{lb}$. Large dull areas; poor air entry; some crepitant sounds at the upper and lower apices of the left lung; catarrhal sounds posteriorly; some prolonged expiration left apex. He was kept in bed for two weeks with persistent antiseptic inhalation. On October 17 th he weighed sounds less marked. On November 14 th he weighed 10 st. $101 \mathrm{lb}$ Had inhaled for about nineteen hours daily. Still had cough, heartburn, and flatulence, for which a mixture was prescribed. Dull areas still diminishing. On December 7 th haemoptysis occurred and he bronght up a large quantity of haemoptysis occurred and he bronght up a large quantity of
blood, about 2 pints. There was recurrence of haemoptysis next day and again two days later, His weight, which had risen to $10 \mathrm{st} .13 \mathrm{lb}$. (a gain of $6 \frac{1}{3} \mathrm{lb}$.), fell to $10 \mathrm{st}$. $1 \mathrm{lb}$. No inhalation was employed for three weeks; but as he began to recover from the effects of the haemoptysis he returned to the practice of continuous inhalation, and he soon began to gain weight rapidly. When I next saw him, on January 9th, 1911, he weighed $10 \mathrm{st} .6 \mathrm{lb}$. It was found that there had been extension of dullness in the right lung. He was inhaling about seventeen hours daily. From this time there was progressive improvement in his condition and in his physical signs, and the weight increased steadily. On June 7 th, 1911, he weighed $11 \mathrm{st} .11 \frac{1}{2} \mathrm{lb}$, a total gain of $19 \mathrm{lb}$. The very hot summer tried him much, but when I saw him on September 25th (almost exactly a year since his first visit) he looked remarkably well and felt well. He then weighed 11 st. $8 \mathrm{lb}$. He was able to do his work.

Case 55.

A schoolmaster, aged 52, sent to me on Octoler 1st, 1910, by Dr. J. J. Edwards of Fulham, suffering from mitral stenosis and from recent pulmonary tuberculosis. At the age of 24 he had rheumatism in his ankles and knees, and was in bed for three weeks; but no subsequent attack. He had had intluenza " many times, three times in the last 18 months." He had lost 2 or $3 \mathrm{lb}$. in weight, his present weight being $8 \mathrm{st}$. 121 $\mathrm{lb}$. There was a presystolic murmur and short thrill at the apex of the heart, a loud first sound without any systolic murmur, and no second sound. No epigastric pulsation; no enlargement of liver. No aortic murmur. He had a short cough, and marked dullness in the characteristic positions, with very feeble air entry, and faint crepitant sounds at both lower apices. No prolonged expiration or andible whisper. He was kept in bed for 10 days, with continuous antiseptic inhalation, and afterwards used the inhaler all night and about 12 hours in the daytime. On October 22nd he had gained $5 \mathrm{lb}$. in the three weeks, and felt that he was "gaining in every way." Cough "altogether gone"-it began to disappear "as soon as he began to wear the much more free, but slight crepitant sounds were still present. He did not cough at all during this visit. On November 24 th he weighed 9 st. 11 lb., a gain of $12 \frac{1}{2} \mathrm{lb}$. in eight weeks. Felt he weighed $9 \mathrm{st} .11 \mathrm{lb}$, a gain of $12 \frac{1}{2} \mathrm{lb}$. in eight weeks. Felt
very much better. No return of cough or sputum. Was still very much better. No return of cough or sp

Twelve months later (November 27th, 1911) Dr. Edwards reported that this patient seemed to be very well, was doing his work as usual, and had no cough.

\section{Case 56.}

A lady who had taken the degree of M.D.Lond., and had worked as a medical missionary in India, where (in November, 1909) she suffered from pleurisy, and lost 2 st. in weight. Her sputum was examined by an expert pathologist, but no tubercle bacilli were found. A well-known physician found no physical signs of disease in her lungs, but by $x$ rays an area of disease at the left apex was detected. She was admitted into a sanatorium, and remained for two months, and gained $8 \mathrm{lb}$. in weight. But her condition again deteriorated, and she was advised to return to the sanatorium. She was, however, sent to me by Dr. Grove of St. Ives, on October 3rd, 1910. Her weight was then 9 st. $5 \mathrm{lb}$. She had had practically no cough for some months, and she brought up only a very little mueus. Yet she had large dull areas at the apices and elsewhere, especially at both lower apices, with very feeble air entry, definite crepitant sound at both apices on the left side, and faintly heard whisper. She was kept in bed for two weeks and practised continuous antiseptic inhalation as advised in my first paper. On antiseptic inhalation as advised in my first paper. On areas were smaller; the air entry was much improved, and the areas were smaller; the air entry was much improved, and the had indigestion and loss of appetite, and lost $4 \mathrm{lb}$. in weight, yet the physical signs in her lungs were still improving. The indigestion gradually disappeared, and on February 4th, 1911, she weighed 9 st. 13 lb. The dull areas were now quite small, and there was no crepitant sound, though the air entry was not yet normal. On March 6th, 1911, she wrote, "I am very well, just rejoicing in a new influx of life and energy, all the more welcome after the long months of lassitude and depression. I have no congh, and only once or twice a week a trace of mucoid expectoration." She was still inhaling about four hours daily and at night. 
On November 17th, 1911, she wrote that she had had no chest symptoms of any kind since her last visit, and had lived an active life, though there was some dyspepsia, and her weight was less that when I last saw her.

She had employed the method of continuous antiseptic inhalation in the case of a patient under her care, with regard to whom a medical man had given a very gloomy prognosis, and who was thought to be "going downhil fast." This patient used the method of antiseptic inhalation for two months, and improved greatly. She then went to live on Dartmoor. She was seen again six months later, and appeared to be very well.

Case $5 \%$.

A man, aged 23, a friend of Case 23, and a patient of Dr. K. C. Mackenzie of Caerphilly, South Wales. His illness began with haemoptysis in March. 1910. In April he was sent to a sanatorium, and remained in it for three months; during his stay his weight rose from $9 \mathrm{st}$. $7 \mathrm{lb}$. to $10 \mathrm{st}$. $7 \mathrm{lb}$. In October a second haemoptysis occurred, with slight pain in the right lung. I saw him first on November 10th, 1910; he then weighed $10 \mathrm{st} .2 \mathrm{lb}$. The dull areas in his lungs were rather large, especially at the lower apices; air entry very defective; some prolonged expiration, crepitant sound, and audible whisper at the right upper apex, and crepitant sounds at the right lower apex. Teeth carious; nasal passages compressed and obstructed. He was advised to use continuous antiseptic inhalation, to give up smoking, and to spray the nose with a cocaine-eucalyptussmoking, and to spray the nose with a cocaine-eucalyptus-
parolein spray. On December 15th, 1910, having carried out these instructions, he stated that he had no cough and that his rectal temperature was only $98.4^{\circ}$. He had gained $9 \mathrm{lb}$. in weight $(10 \mathrm{st}$. $11 \mathrm{lb}$.) in the five weeks; all the dull areas were markedly smaller, and the only auscultatory signs were harsh inspiration and slight crepitus at the right upper apex, with slight crepitus ilso at the lower apex. In January, 1911, he had an attack of vomiting and diarrhoea lasting three days-apparently a food poisoning, as his father had similar symptoms. It was therefore not surprising that on February 2nd, 1911, he had lost $2 \mathrm{lb}$. in weight; yet in spite of this his physical signs, both by percussion and by auscultation, were better than at the last visit. He was now inhaling about six hours daily and at night. On May 10th, 1911, though in lighter clothes, he weighed 10 st. $9 \frac{1}{1 b}$; the dull areas were smaller than in February, and the only auscultatory sign was slight bronchial breathing, without any crepitant sound or bronchophony, in the second. right interspace. The sputum had been examined about month previously. The report stated that there were "still some bacilli, but mnch fewer than before."

This patient lives at Cardiff and I have not seen him again, but I regret to hear that in $J$ une he had repeated haemoptysis and that his present condition is causing anxiety to his friends

\section{Case 58.}

A young man of 19, brought by Dr. Ashton of Battersea, December 29 th, 1910, on account of a congh which had lasted. for three months, and occasional night sweats. Weight, 8 st. $1:$ lb. He had a ioose cough, with typical dull areas of moderate size, some prolonged expiration, with slight bronchophony and andible whisper at the right upper apex, and some crepitant sounds (still audible after a cough) at both upper apices. He was kept in bed for two weeks and practised continuous antiwas kept in bed for two weeks and practised continuous antiseptic inhalation. On January 27th, 1911, his weight was
$8 \mathrm{st} .3 \mathrm{lb}$., his cough was " much better," and sputum scanty. 8 st. 3 lb., his cough was "much better," and sputum scanty.
The dull areas were all smaller, the prolonged expiration and bronchophony had vanished, and only slight crepitant sound remained. He was now permitted to take an hour's walk each morning, but instead of limiting himself to one hour's exercise, he walked for four hours daily! The consequence was a distinct relapse, the temperature rose to $100^{\circ}$ and on February 24th he was found to have lost $1 \mathrm{lb}$. ; all his dull areas were larger, and some interrupted respiration could be heard at his left apex. He was sent to bed again for two $w e 3 k s$, and made to inhale without intermission. On March 24th he had regained the los pound ( $8 \mathrm{st} .3 \mathrm{lb}$.), and the physical signs had again improved. After this he used the inhaler every night, but very little during the day. His improvement continued, and in June he resumed his work. I examined him again on September 27th, 1911; he looked and felt very well. His weight was still $8 \mathrm{st}$. $3 \mathrm{lb}$. His physical signs were nearly normal.

In January, 1912, he was still quite well.

Case 59.

A clerk of works, aged 44, sent to me by Dr. Mowll of Surbiton, February 10th, 1911, on account of slight haemoptysis three weeks ago, repeated a week ago. He had had a slight hacking cough for a few days only. There was some complaint of indigestion, with flatulence and palpitation. He had been costive for some years, and had had piles. His weight was 9 st $71 \mathrm{~b}$. His heart was normal. His muscular system was well developed (the result of a six months' course of physical exercises).

Dull areas were found in his lungs, in the positions characteristic of a tuberculous infection, the largest being that at the right lower apex. At this region a slight crepitant sound, possibly frictional, could be heard, and he complained of slight pain in the region of the right nipple on taking a deep inspiration. The only other auscultatory sign was a feebleness of air entry over the apical regions. Medicine was prescribed for his entry orer the apical regions. Medicine was prescribed for his
dyspepsia and constipation; he was confined to bed for a week, and advised to practise continuous antiseptic inhalation

I saw him a sezond time on March 17 th. His weight was 10 st. $4 \frac{1}{2} \mathrm{lb}$; ; in the five weeks he had gained $11 \frac{1}{2} \mathrm{lb}$. All the C dull areas were smaller: no rub or crepitant sound could be heard anywhere. There was no pain on breathing, and the air entry was more free. He had been back at work for two weeks, using the inhaler in his office whenever possible. He continued to improve till June, when in the very hot weather he felt faint and had slight haemoptysis. He came to me a third time on October 19th, 1911, his weight was then 10st. $2 \frac{1}{\mathrm{a}} \mathrm{lb}$; ; he had no cough, but the physical signs in his lungs showed a slight increase. He was sent to bed for ten days, and practised continuous antiseptic inhalation once more. On November $23 \mathrm{rd}$, 1911, he was found to have gained $2 \mathrm{lb}$., and thus regained his normal weight of $10 \mathrm{st}$. $4 \frac{\mathrm{l}}{\mathrm{l}} \mathrm{b}$. There was no sputum and practionly auscultatory sign was a defect of air entry over these areas.

$$
\text { Case } 60 .
$$

A schoolmistress, aged 29, sent by Dr. Muir of Burdett Road, February llth, 1911. Indigestion for a year, frequent "colds," but "phlegm at back of throat." Dull areas, fairly large, were found in all the positions characteristic of a tuberculous infection; the largest were at the right upper and lower apices. The air entry was extremely defective in these positions, and some crepitant sound could be heard at the right lower apex (but nowhere else). No prolonged expiration. Weight $7 \mathrm{st}$. $41 \mathrm{lb}$. (last summer it was 7 st. $6 \mathrm{lb}$.). She was sent to bed for ten days, and practised continuous antiseptic inhalation. A tonic mixture was prescribed; milk and malted milk (as in all these cases) was taken four times daily. On March 4th, 1911, she had gained 4 lb. in the three weeks, felt and looked much better. The dull areas were all smaller, the air entry was distinctly improved though still defective, and the crepitant sounds had nearly disappeared. On April 1st she had gained $2 \mathrm{lb}$. more (7 st. 101 lb.), and further improvernent in the physical signs was recorded. She was now permitted to return to her work as a school teacher. On June 3rd she weighed rather less $(7$ st. $8 \mathrm{lb}$.), but she felt quite well and had done her full work for two months: The physical signs were now extremely slight. On September 30tb, 1911, she appeared to be quite well and had done her full work. She still practised inhalation at night.

\section{Case 61.}

A district nurse, aged 27, a patient of Dr. Adair of Belfast. "Pneumonia" two years ago. At work in England eighteen months. Frequent "colds"; pleurisy two weeks before I first saw her on February 19th, 1911. Weight 8 st. 9 lb. (had been 9 st. last Christmas). Typical dull areas, of which the largest were at her right apex; very defective air entry; catarrhal double crepitus at both upper and at the right lower apices; whisper and had a frequent short cough. She obtained leave of absence for three months, went back to her home in Belfast, staved in bed for three weeks, and practised continuous antiseptic inhala. tion for a month, after which she gradually lessened the time of inhalation. The cough ceased after about two months. She
came to mo a second time on June 8th, 1911. She looked and felt better; all her dull areas were much smaller, the air entry was good everywhere, and no crepitant sound was audible. Only at the right apex posteriorly there was slight prolongation of expiration and slight bronchophony. She was permitted to return to her work as a district nurse. I saw her for the third time on October 13th, 1911. During all this hot and most trying summer she had worked very hard, and during some weeks had

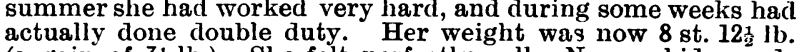
(a gain of $3 \frac{1}{2} \mathrm{lb}$.). She felt. perfectly well. No morbid sounds could be detected in her lungs, and all the dull areas were now very small. She was still inhaling for two hours daily and at night.

\section{Case 62.}

A young man, aged 19, seen with Dr. Schaub of Harlesden, February 20th, 1911. He had been well until quite recently, but had suffered from "a cold" for two or three weeks. Dr. Schaub examined his sputum four days ago, and found " tubercle bacilli in good mumber," and a second specimen two davs ago was "croucded vith tubercle bacilli." The patient looked depressed, and had a slight frequent short cough. Weight, 11 st. $2 \frac{1}{3} \mathrm{lb}$. Typical dull areas in his lungs, the largest being at the right upper and lower apices. Poor air entry and some crepitant sound at all four apices, whisper faintly audible at the right apex; no prolonged expiration. He was advised to remain in bed for ten days, and to practise continuous antiseptic inhalation.

I saw him a second time on March 13th, 1911; the weight was then 11 st $7 \frac{1}{2} 1 \mathrm{~b}$., a gain of $5 \mathrm{lb}$. in the three weeks. He felt "quite well," and wished to be allowed to play football! The cough was much lessened in three days after beginning the inhalation. There was now cough only in the early morning, and very little sputum. Dr. Schaub examined this for the third time three days ago, and had "difficulty in finding bacilli." The dull areas were all smaller, the air entry more free though not yet normal, and the crepitant sounds were much diminished. He was advised to continue the persistent inhalation, allowing an interval of two hours every morning. A month later (April 11th, 1911) Dr. Schaub reported that there had been no sputum for a week, and his evening temperature was normal. The dull areas were less than at the last visit; no crepitant sound could be heard ; there was a little prolongation of the expiration at the right apex only.

On May 16th, 1911, he stated that he had continued the inhalation six hours daily and at night, and that he had had no cough and no sputum for a month. He looked remarkably
well, and had gained $2 \mathrm{lb}$. in weight (11 st. 913 lb.), a total 
gain of $7 \mathrm{lb}$. The dull areas were now all very small, and no morbid sounds were audible.

On December 3rd, 1911, Dr. Schaub reported that this patient had gone on well, that he had been at work for a month, and that he was keeping np his weight. He stlll wore the inhaler at night.

On January 16th, 1912, he was still quite well, and had no cough. He had been in full work regularly for three months.

Case 63.

A girl aged 13, seen with Dr. Hickley of South Lambeth Aoad, February 21st, 1911. Out of health two months, abdominal aiscomfort, cough, and some pyrexia $\left(100^{\circ} \mathrm{F}\right.$.) for a few days. She was a pale, thin girl, with a pulse-rate of 140 and respiration-rate of 36 . The abdomen was swollen and rather tender; obvious ascites was present, but no lumps or bands could be felt. The lungs showed dull areas in the positions characteristic of tuberculous disease, the largest of them situated at the right upper and lower apices. There was defective air entry, and some slight crepitant sound.

In view of the general condition and of the implication of both thorax and abdomen, a very unfavourable prognosis was given. She was kept at rest in bed, and fed on milk with malted milk every three hours. The windows were kept open and she wore constantly a Yeo's inhaler, using the antiseptic solution described in my first paper.

Three weeks later Dr. Hickley reported that the child liked her inhaler so much that "she will not be parted from it"; that her cough was better, and the circumferencs of the abdomen a little less. He detected a lump in the lumbar region. There had been some diarrhoea, relieved by medicine. I saw her a second time with Dr. Hickley on April 11th, 1911. There had been no cough for a long time, and the temperature was now always normal or subnormal. All the dull areas in the lungs were much smaller. The circumference of the abdomen was $1 \frac{2}{2}$ in. less than in February, and no ascitic fluid could be detected. There was a resistant region in the abdomen to the left of the umbilicus, and some enlarged giands in the right iliac fossa. The child was very thin ; she had refused to take the milk and malted milk. She promised to do better in this respect, and the parents were advised to insist on her taking this nourishment regularly. The promise was carried out, and Dr. Hickley informs me that she improved very much. Three months later she was so much better that she was able to go to stay with friends in Wales. When she left London in July Dr. Hickley could find no evidence of disease in her lungs, and the abdominel lump was much smaller. But a relapse must have occurred before long, for she died in September. Possibly this relapse may have been due to exhaustion caused by the great heat of last summer, which has caused other tuberculous cases under observation to deteriorate. Thus the gloomy prognosis given at first was justified; yet the temporary improvement while under treatment by continuous antiseptic inhalation was most striking.

Case 64.

A schoolmistress, aged 45 brought by Dr. Chesters of Bromley, February 22nd, 1911. Cough for about a month; no haemoptysis; slight indigestion; sleep disturbed by cough. Temperature $99^{\circ}$ to $100^{\circ}$; pulse 96 ; weight $8 \mathrm{st}$. $12 \mathrm{lb}$. Dull areas in both lungs, in the positions characteristic of pulmonary taberculosis, the largest being at the right upper and lower apices. There was deficient air entry, a little prolongation of expiration, and slight bronchophony at the right upper apex, and slight crepitant sounds at both lower apices. She was advised to remain in bed for ten days; and to practise continuous antiseptic inhalation.

On March 12th Dr. Chesters telephoned: "She is doing splendidly." Three days later he brought her to me again. Her weight was then $9 \mathrm{st}$. $4 \mathrm{lb}$., a gain of $6 \mathrm{lb}$. in three weeks. She had not coughed since the second day of her use of the inhaler. Now no sputum. Temperature normal for the last week. All the dull areas were distinctly smaller, the air entry was more free, and the crepitant sounds had almost entirely disappeared.

I saw her a third time on April 11th, 1911. The temperature had been normal since the last visit. There was no cough and no sputum. The weight was still 9 st. $4 \mathrm{lb}$. The dull areas were smaller than in March, and the auscultatory signs were nearly normal. In December, 1911, Dr. Chesters reported that she was in excellent health, in spite of the trying summer and of extra work and some anxieties. Her weight had risen to 9 st. $7 \mathrm{lb}$.

Case 65.

A clerk, aged 22, sent by Dr. Edwards of Fulham, March 2nd, 1911. Pain on breathing from time to time for several years. Occasional cough, with some phlegm ; no haemoptysis ; slight dyspepsia. Dr. Edwards had examined the sputum, but found no bacilli. The patient was anaemic. His weight was 9 st. $9 \frac{1}{2} \mathrm{lb}$. eight months ago it was 9 st. $11 \mathrm{lb}$. Dull areas were found in all the positions characteristic of pulmonary tuberculosis, the largest being at the left upper and lower apices. There was much defect of air entry, and a little crepitant sound at both upper apices in front. Posteriorly, at the left upper apex the inspiration was somewhat harsh, and the expiration was slightly prolonged; at the three other apices hardly any entry of air could be heard. . He was kept in bed for ten days, and practised continuous antiseptic inhalation. He was forbidden to smoke. An alkaline tonic mixture was given before meals.

On March 23rd, 1911, his weight was 9 st. 121 lb., a gain of $3 \mathrm{lb}$. in three weeks; he felt and looked better, his cough had disappeared, dyspepsia much less, dull areas smaller, and air entry much more free. Still slight crepitant sound at both upper apices. On April 20th, 1911, he felt "very well indeed," and his weight was 9 st. $13 \mathrm{lb}$. Iron was prescribed for his anaemia, and he was permitted to go back to work. On May 30th, 1911, he was still very well, though he had worked in a lawyer's office for four hours daily. He had continued the inhalation six hours daily, and at night. On September 18th, 1911, he had worked from 10 a.m. to 3 p.m. regularly since July, except during a three weeks' holiday. In spite of the trying heat he had remained very well. The dull areas were now small, the entry of air satisfactory, and morbid sounds on auscultation almost absent. He was advised to use his inhaler at night for a further period of six months.

A cough since October. No haemoptysis. Some sputum Ho grown thinner lately. Evening temperature $99.5^{\circ} \mathrm{F}$. Dull areas were found at all four apices the air ene $99.5^{\circ} \mathrm{F}$. Dull and some crepitant sound could be heard above the right nipple. He remained in bed and practised continuous antiseptic inhalation. Six. weeks later he was brought to my house by Dr. Ashton, who reported that " the temperature continued at $99.5^{\circ} \mathrm{F}$. to $100^{\circ} \mathrm{F}$. every evening until two days ago; last evening only $99^{\circ} \mathrm{F}$.; in the morning usually $98^{\circ} \mathrm{F}$." ' The patient said that his cough was "ever so much better." His weight was now 9 st. $3 \frac{1}{2} \mathrm{lb}$.; before Christmas it was 8 st. $7 \mathrm{lb}$., and Dr. Ashton stated that he had lost flesh considerably before I saw him in March, so that he appeared to have gained fully a stone in weight during the six weeks of treatment. The dull areas were all smaller. There was now some prolonged expiratory sound at the right upper apex, both in front and behind, but hardly any crepitant sounds. On June 15th, 1911, I saw him again at his own home with Dr. Ashton. He was still inhaling for eight hours daily and at night. There was now practically no cough, and the temperature had not been above the normal for a long time. He looked plump and well. His weight was now 9 st. $5 \frac{1}{2} \mathrm{lb}$. The dull areas at his apices were distinctly smaller; no crepitant sounds could be heard, but there was still a little prolonged expiration at the right apex.

In January, 1912, Dr. Ashton informed me that this patient was still doing well.

A lady, aged 26, brought by Dr. Hickley of South Lambeth Road, March 14th, 1911. Had suffered from more or less indigestion for five years, but had coughed only for about a fortnight. The cough kept her awake at night, and there had

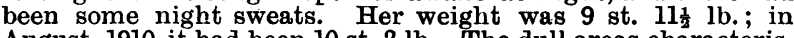
August, 1910, it had been 10 st. $2 \mathrm{lb}$. The dull areas characteristic of pulmonary tuberculosis were found in her lungs, with defective air entry, and some prolongation of expiration, with very slight crepitant sound, in the right suprascapular fossa only. She was kept in bed för a week, and practised continuous antiseptic inhalation for seven weeks. On May 2nd, 1911, I saw her a second time, when she felt "very much better." The cough "lingered on for a week or two," but there had been no cough for the last three weeks. The appetite was "very good," and she slept well. Her weight had increased by $11 \frac{1}{2} \mathrm{lb}$. in seven weeks, and was now $10 \mathrm{st}$. $9 \mathrm{lb}$. She looked very well. All the dull areas were smaller, the air entry was more free, and hardly any morbid sound could be detected.

She was instructed to use breathing exercises twice daily, and advised to inhale at night and for six hours daily. On May 3lst, 1911 , she felt "very well indeed," except for slight indigestion. On July 28th, 1911, her weight was found to be 10 st. $10 \frac{1}{2} \mathrm{lb}$.-a total gain of $13 \mathrm{lb}$. There was no cough at all: no morbid sounds could be heard in her lungs, and the dull areas were all quite small. She was considered to be cured, but was advised to continue the inhalations for four hours daily for a further period.

Case 68.

A lad5, aged 22, seen with Dr. Ehrmann of Camden Road, April 3rd, 1911. Well until ten days ago, when she was overtired by a dance lasting till 5 a.m.; two days later there was slight sore throat; three days later her temperature was found to be $100^{\circ} \mathrm{F}$; ; it was now $101^{\circ}$ in the morning and $102^{\circ}$ in the evening. Slight cough, but no sputum. On examination of her chest it was found that she had small areas of dullness in all the positions characteristic of an early pulmonary tuberculosis, the largest being at the right upper and lower apices. Auscultatory signs were almost absent. She was directed to remain in bed for a week, and to practise continuous antiseptic inhalation for three weeks. On April 24th, 1911, Dr. Ehrmann brought her to my house; her weight was then 10 st. $81 \mathrm{~b}$. She had inhaled as directed; the temperature fell to normal in three days, and had not again been above the normal. The cough had gradually lessened; it disappeared three days ago. No sputum. She felt quite well. The dull areas were distinctly smaller; there was good air entry in front, with very slight crepitant sound at the end of inspiration. There was a defective air entry at the right upper apex behind, and very slight crepitant sound at the end of inspiration at the right lower apex; nothing else abnormal. She was advised to continue the persistent inhalation for three weeks longer, except for two hours in the morning and an hour in the afternoon. On May 17th, 1911, her weight was 10 st. $10 \frac{1}{2} \mathrm{lb}$., a gain of $2 \frac{1}{2} \mathrm{lb}$. She felt quite well. The dull areas were now very small, and the only abnormalities detected by auscultation were slight defect of air entry and the slightest possible crepitus. She was considered to be cured, and advised to practise breathing exercises and still to use her inhaler for three hours daily. 
In January, 1912, Dr. Ehrmann kindly informed me that this lady was still quite well and fully able to perform all her usual occupations,

\section{Case 69.}

A lady, aged 39, sent by Dr. Edwards of Fulham, May 31st 1911. Cough in winter time for some years; very subject to "colds going on to bronchitis." For about three years has had asthmatic attacks, which recur about once a month. Since March, 1911, she has had continual cough, with shortness of breath and yellow phlegm, and has lost weight. Anorexia, dyspepsia, flatulence, and disturbed sleep.

Weight 6 st. 91 lb. On examination of her chest the signs found were not those of a generalized bronchitis: they were limited to the regions affected in early pulmonary tuberculnsis. There were rather large areas of dullness at the characteristic positions at the four apices and elsewhere; the air-entry at the apices was very defective, and prolonged expiration, broncbophony, and audible whisper were heard at both upper and lower apices on the right side posteriorly. She was kegt in bed for two weeks, and practised

a tonic was presoribed.

On June 28 th she had gained a pound in weight, and her condition was slightly improved, but she still suffered from asthma, which disturbed her sleep. A nasal spray of cocaine, eucalyptus, and parolein was therefore prescribed, to be used three times a day, and the continuous antiseptic inhalation was free from asthma since she had used the nasal spray ${ }^{2}$ the physical signs in her lungs were decidedly improved. On September 23rd, 1911, she felt and looked better, in spite of the very trying summer; the dull areas were still smaller and the air entry much improved, but there was now distinct evidence of a small (dry) cavity at the right apex posteriorly. She was advised to persevere with the inhalations, and to practise breathing exercises.

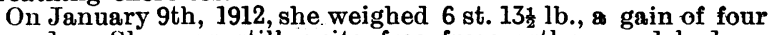
pounds. She was still quite free from asthma and had no cough, though on some mornings she brought up a small quantity of phlegm on waking. She was still using the inhaler at night and for four hours in the daytime. Her dull areas were at night and for four hours in the daytime. Her duil areas were now very much smaller, and the only morbid sound detected She was dismissed as cured, but advised to use the inhaler two to three hours daily for the next six months.

Case 70.

The matron of a convalescent home (formerly a hospital sister) came to me on August 5th, 1911, on account of a general feeling of illness, and occasional night sweats, with loss of weight ( $5 \frac{1}{2} \mathrm{lb}$. during the last month). She had, however, no cough at all, and no pain in the chest. On examination the only sign of disease that could be discovered was the existence of sign of disease that could be discovered was the existence of
small dull areas in both lungs, in the positions characteristic of an incipient pulmonary tuberculosis, and very slight catarrhal sound at both apices in front. The signs might easily have been overlooked altogether.

She was unable to begin a course of treatment until a week later, when arrangements had been made to release her from duty. During this week there was a further loss of weight to the amount of $2 \mathrm{lb}$. But during the first week of treatment (in bed) by continuous antiseptic inhalation she regained these $2 \mathrm{lb}$. and in the following week gained $2 \frac{1}{2} \mathrm{lb}$. more. On August 24th, 1911, she wrote: "Alresdy life is so much more worth living, and that excessively tired feeling has almost vanished. I can hardly believe that it is only three weeks since I felt such an absolute wreck." On September 1st, 1911, she wrote: "I gained another $2 \frac{1}{4} \mathrm{lb}$. this week-that makes $43 \mathrm{lb}$. My temperature is much more steady ; at first it was generally $96.4^{\circ}$ in perature is much morning and $99^{\circ}$ at night. Now it is $97.4^{\circ}-98^{\circ}$ in the morning and $98^{\circ}-98.2^{\circ}$ at night. Also I don't have the night sweats ing and

On September 16th, 1911, all her dull areas were found to be smaller, and the catarrhal sounds at the auices had nearly disappeared. There were some digestive difficulties in October, but when these were overcom $\epsilon$ she again gained weight. Up to the end of this month she had been using the inhaler persistently, except du'ifg an hour's exercise each morning. She now reduced the time of inhalation to eight hours in the daytime, and at night; with a further reduction of one hour every fortnight. On December 9th she wrote: "I am still feeling quite well, my weight is quite steady, and I feel equal to anything. I can't understand anybody having a doubt as to the efficacy of the treatment: I wish I could satisfactorily explain how different in every way I feel, and have felt since shortly after taking up the treatment.

On December 29th, 1911, the dull areas were found to be still further lessened and the air entry was good. Only the faintest crepitant sound (probably pleur ul) was detected at one apex.

On February lst, 1912, she was found to be quite well, and no morbid sounds could be detected. She has since resumed her duties.

THE fourth Congress of Physio-therapy of French-speaking doctors will be held in Paris at Easter, under the presidency of Dr. Georges Rosenthal. The Vice-Presidents are Drs. Hirschberg, Pierre Kouindjy, and Mesnard, of Paris ; Dr. Edgar Cyriax, of London; and Dr. Profanter, of Franzenbad.
ON PEREZ'S SIGN : AND AUDIBLE MOTOR CRACKLES.

WITH SPECIAL REFERENCE TO THE INTRATHORACIO TISSUE SOUNDS ELICITED BY ARTICULAR MOVEMENT IN THEIR RELATION TO THE DIAGNOSIS OF TUBERCULOSIS.

BY

WILLIAM EWART, M.D.CANTAB., F.R.C.P., CONBULTING PHYSICIAN TO ST. GEORGE'S HOSPITAL AND TO THE BELGRAVE HOSPITAL FOR CHILDREN.

The stethoscopic sounds classified by Laënnec are mostly due to the conflict or to the reciprocal movements of fluid and of air, ranging from the capillary "pneumonic crepita. tions" to the loud gurgling of "crying bowels," or to the "water wheel" churnings of hydro-pneumopericardium. But they also include a long scale of "dry" sounds, either from solid vibrations such as the fine "grazing" or the coarse "new leather creaking" sounds of pericarditis, or the fine and the coarse sounds of pulmonary emphysema or fibrosis ; or else from mainly aërial vibrations, like those elicited by pressure in subcutaneous emphysema. Fluid, when unmixed with air, as in the infiltrations of subcutaneous oedema or in the bulk of a serous effusion, has a silencing effect. It might almost be said that fluid, unmixed with air, is "parent of sweet sounds yet mute for ever" but for the loud report of joint dislocation sounds where there is no air conduction but slight moisture only within the joint, and which Dr. Garrod has ingeniously termed a non lucendo "articular vacuum sounds." These might perhaps be due to the solid vibrations of some forcible membranous flapping, like the analogous report of the sigmoid valve flap at the moment of its tension.

Perez's sign has done more than anything else for the study of the dry vibration sounds which make up the immense majority of the "tissue-movement sounds," by directing the stethoscope to their observation, although we were already familiar with the "muscular rumble." As it has only recently brought that study into more general use, we are saved the burden of a long bibliography; and any investigator would enjoy the rare opportunity of commanding a comprehensive view of the entire subject at the start. This communication is offered as a brief introdustion to that survey.

\section{Perez's 'Sign.}

Perez's sign consists essentially in the production of sounds audible over the upper thoracic surface on actively or passively moving the arms at the shoulder-joint, and particularly on raising or lowering them. It was originally described by him, in a case of mediastino-pericarditis, as due to intrathoracic sounds elicited by these movements in the upper part of the chest; and it has been referred to in that connexion by Fowler and Godlee, ${ }^{1}$ by Frederick Roberts, ${ }^{2}$ and also in Gould's Practitioners' Dictionary, and in Lippincott's new Medieal Dictionary. The following description is from Dr. Perez's own pen:

The original case in which this physical sign was discovered and subsequently described in the BRITISH MEDICAL JOURNAL ${ }^{3}$ was commented on very thoroughly by the late Dr. Thomas Harris, of Manchester, and was examined by Sir Richard Douglas Powell, Sir Kingston Fowler, Dr. Wm. Ewart, Dr. Herbert Spencer, and others. The maximum intensity of the loud friction sounds or crackles was over the mid-sternum although the sounds could also be distinctly heard over both scapular regions. The patient having had for many years attacks of what was considered to be dry pericarditis attended with excruciating, in fact anginal, pain, no reasonable doubt could be entertained that inflammatory adhesions existed, at any rate, in the anterior mediastinum, and that they were probably of a chronic tubercular nature, the patient having had formerly an infiltration of one of the apices of the lungs, which was diagnosed by the late Sir Wm. Gull. The various cardiac murmurs which were heard by some eminent London physicians, but not confirmed by others, point in my mind to extra cardiac murmurs produced by adhesions.

Its Scope in Relation to Articuitations.-As regards the interpretation of these stethoscopic sounds, a critical examination of the case led the writer to suggest as an alternative explanation their possibly extrathoracic articular origin-namely, in the joints which were subjected to movement; for I could hear the same sounds when the stethoscope was applied either to the shoulderjoint or to the sterno-clavicular articulation, and also along 